\title{
Progressive cauda equina syndrome and extensive calification/ossification of the lumbosacral meninges
}

\author{
J ROTÉS-QUEROL, ${ }^{1}$ E TOLOSA, ${ }^{2}$ R ROSELLO, ${ }^{1}$ AND J GRANADOS
}

From the ${ }^{\prime}$ Rheumatology Service, and the ${ }^{2}$ Neurology Service, Hospital Clínico y Provincial, Facultad de Medicina, C/ Casanova 143, Barcelona 08036, Spain and the ${ }^{3}$ Rheumatology Service, Hospital de la Mutua. de Tarrasa, Tarrasa, (Provincia de Barcelona), Spain

SUMmARY A patient with longstanding ankylosing spondylitis (AS) developed a cauda equina syndrome. The myelogram showed a block at the L2 level. Vertebral computerised tomography showed calcification in the centre of the spinal canal. The patient also had features suggestive of a diffuse idiopathic skeletal hyperostosis (DISH). Meningeal calcification has never been reported in AS, so we suggest that this is related to an associated DISH. Cauda equina syndrome has not been described in DISH, and calcification of meninges has not been reported in AS, so we suggest that the meningeal calcifications and associated cauda equina syndrome are related to DISH.

Key words: diffuse idiopathic skeletal hyperostosis, ankylosing spondylitis, meningeal calcification.

The appearance of a cauda equina syndrome in patients with ankylosing spondylitis (AS) is well known, and nearly 30 cases of this association have been published, most of them recorded by myelography or computerised tomography (CT). ${ }^{1-10}$ Posterior saccular diverticula are seen when myelography is performed in the supine position. The CT shows erosions in the internal aspect of the posterior vertebral arch. This latter technique has been proposed by some authors ${ }^{x-11}$ as the best diagnostic procedure.

In diffuse idiopathic skeletal hyperostosis (DISH) there are ossifications in the posterior longitudinal ligament (PLL) and ligamentum flavum, with myelocompressive syndromes in the cervical region and rarely in the dorsal region. ${ }^{12-15}$ We do not know of any case involving the lumbar spine. Here we report the case of a patient with advanced AS and radiological findings suggestive of DISH who developed a cauda equina syndrome secondary to extensive calcification or ossification, or both, at the dura and leptomeninges at the lumbosacral level.

Accepted for publication 23 October 1984.

Correspondence to Dr J Rotés-Qucrol. Servicio de Reumatología, Hospital Clínico y Provincial. C/ Casanova 143. Barcelona 08036. Spain.

\section{Case report}

The patient was a 63-year-old female. In 1977 when she was 57 she consulted our Rheumatology Clinic because of back pain and stiffness that had lasted for more than 15 years. It had an inflammatory pattern with night pain, and she had long periods of pain and swelling of the knees that were repeatedly infiltrated with corticoids. The swelling had been continuous for the last five months. During these years she became progressively more stiff and developed a kyphosis. For the last five years she also complained of pain in the anterior thighs with walking. In addition she had hyperthyroidism which had been treated with carbimazole for the last five years.

Examination showed a rigid spine with smooth and gross kyphosis, the lumbar lordosis had disappeared, and the distance from the occiput to the wall was $7 \mathrm{~cm}$. Chest expansion was limited to $2 \mathrm{~cm}$. The hips and knees were stiff, with little flexion. The shoulders were also stiff, with an abduction of $160^{\circ}$ at the right and $100^{\circ}$ at the left.

Radiology showed bilateral sacroiliac fusion (grade IV) with generalised syndesmophytes, squar- 


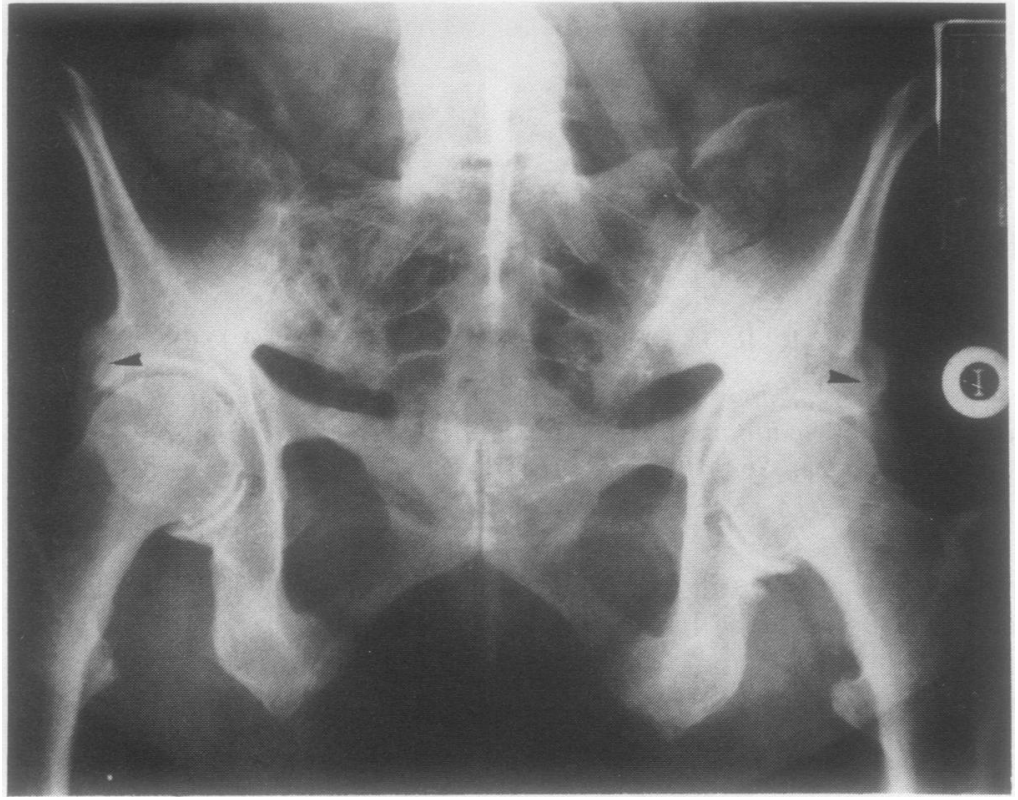

ing of dorsal and lumbar vertebrae, and facetal joint fusion, characteristic of advanced AS (Fig. 1). There were also para-articular, thick squared osteophytes on the cotyloid tuberosity without alteration in joint space, and ligamentous ossification with large bone spurs on the anterior face of the patellas, typical of a peripheral DISH. An $x$-ray of the dorsal column (Fig. 2) showed a thick ossified band in the area of the PLL from D3 to D7. HLA-B27 was negative.

At this stage a diagnosis of advanced AS was made, with lesions characteristic of DISH at hips, patellas, and dorsal PPL. She received phenylbutazone $200 \mathrm{mg}$ daily and physiotherapy which caused diurnal and nocturnal pain to disappear. Later she was maintained free of pain with phenylbutazone $100 \mathrm{mg}$ a day. Two years ago she began to complain of numbness in her left leg with progressive wasting and weakness; similar symptoms appeared shortly after in the right leg hindering her walking. On neurological examination she could neither walk on her heels nor dorsiflex her feet or right great toe. The right patellar and both ankle jerks were absent. Sensation was lost over L4, L5, and S1 left and L5 right. A diagnosis of an asymmetric cauda equina syndrome was made. Electromyography showed bilateral involvement of L5.

A myelogram by the suboccipital route (Fig. 3) showed a contrast column block at the L2 level. Diverticula were not observed.

Vertebral computerised tomography from L2 to L5 (Fig. 4) showed at all levels calcification in the

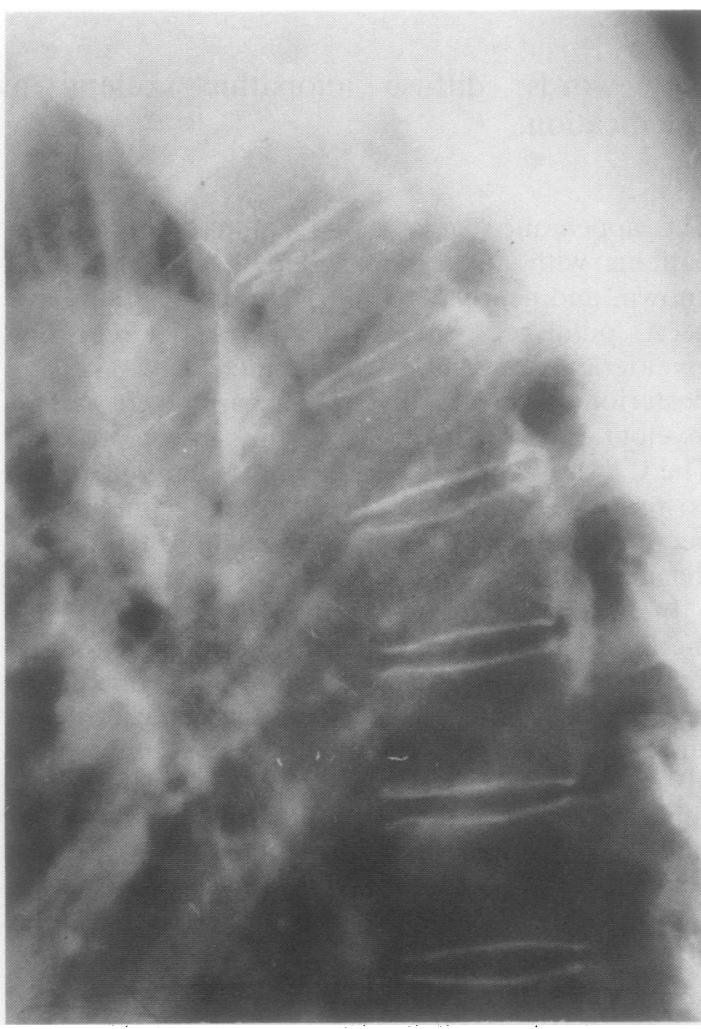

Fig. 2 Dorsal column with a thick ossified band corresponding to the PLL from D3 to D7.
Fig. $1 A$ view of the lumbar spine with bilateral sacroiliac fusion, generalised syndesmophytes, and facetal joint involvement. Thick bony plasters on acetabulum typical of DISH (arrowheads). 


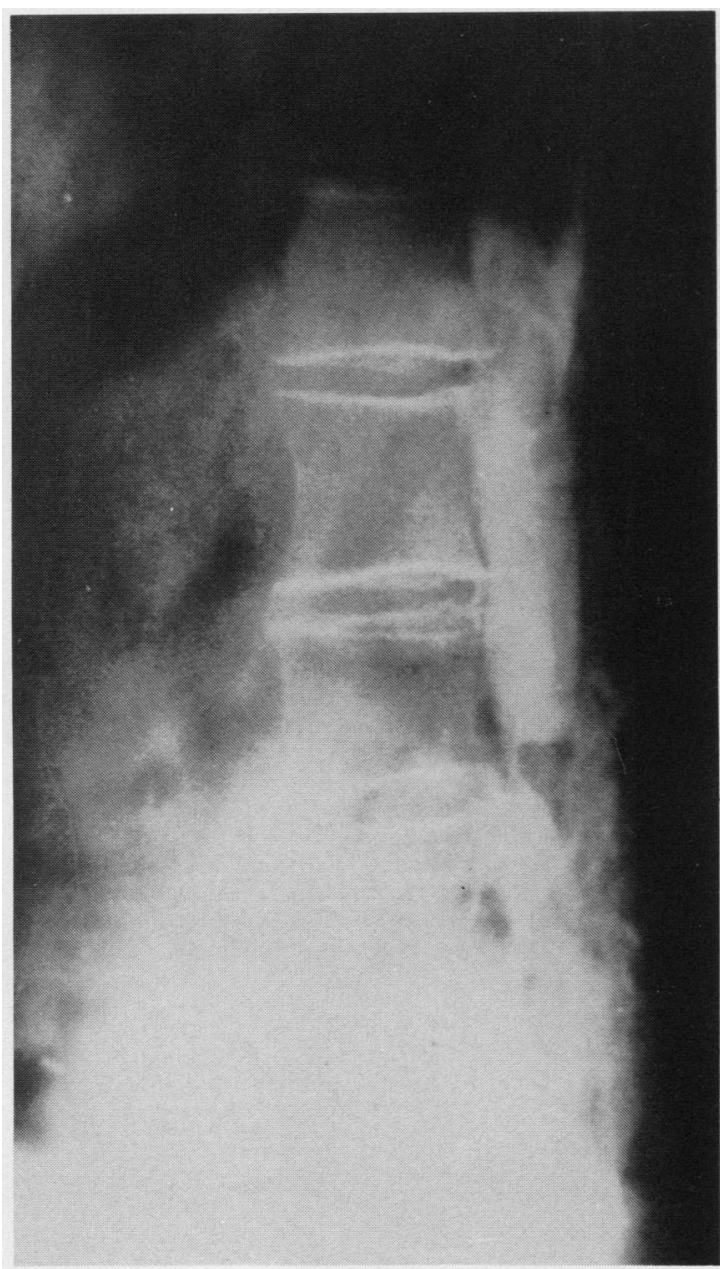

Fig. 3 Myelogram with a block at the L2 level.

centre of the spinal canal, which was circular, not adherent to bone, and seemed to be a continuous longitudinal calcification/ossification of meninges.

The patient underwent decompressive laminectomy from L1 to L4. The surgeon found calcified tissue that included the interspinous ligament and ligamentum flavum and also the meninges with the spinal roots. After surgery she developed urinary and faecal incontinence, but these have gradually improved.

\section{Discussion}

The patient presented here developed a progressive cauda equina syndrome with extensive calcification and ossification of PLL and flavum spinal ligaments

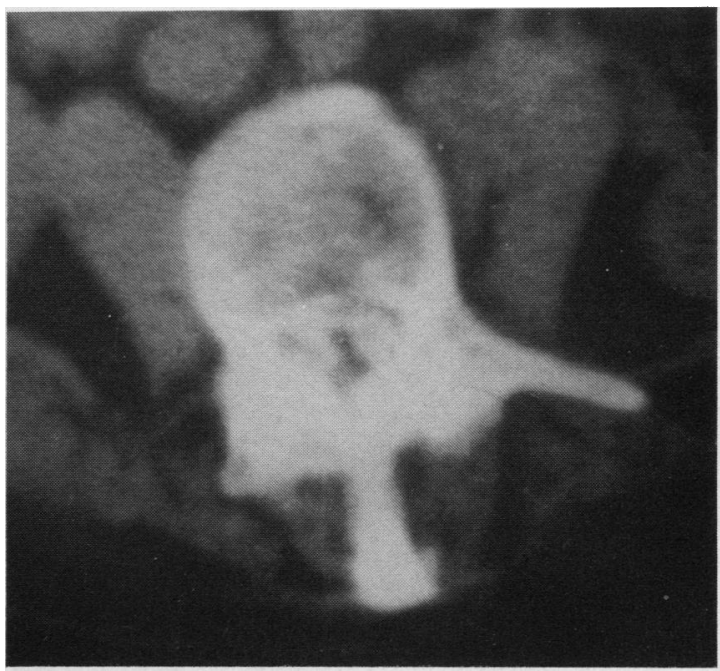

Fig. $4 C T$ in L3 with a calcification in the centre of the spinal canal around the roots of the cauda equina. The same image was found from L2 to S1.

and of the dura and leptomeninges at the lumbosacral level. We suggest that this patient has AS because of her long standing vertebral pain with inflammation, the episodes of knee arthritis, stiffness of hips and shoulders, and bilateral fusion of sacroiliac joints, the squaring of the dorsolumbar vertebrae, and the fine marginal syndesmophytes.

In view of these data the HLA-B27, although negative, cannot negate the diagnosis. This case raises the question of the nosologic classification of the calcification/ossification in the cauda equina. We have reviewed the cauda equina syndromes in AS published up to the present ${ }^{1-11}$ and have not found any similar cases. AS produces a cauda equina syndrome with erosions in the posterior arch and diverticular in the dural sac, anomalies that could not be demonstrated in our patient, but ligamentous and meningeal calcification involving the roots never occurs. Moreover we do not know of any case with leptomeningeal calcification in AS.

DISH can produce calcification/ossification in the cranial meninges in the form of internal frontal hyperostosis and ossification of the falx cerebri and Grüber ligament. ${ }^{12}$

In our patient the peripheral DISH is evident in the thick squared para-articular osteophytes at the acetabulum of both hips without alteration in joint spaces and the thick osseous aposition at the anterior face of the patellas. A lateral dorsal column x-ray showed an ossified PLL from D3 to D7 (Fig. 2). 
Although in the original descriptions PLL calcifications were not related to $\mathrm{DISH}$, later publications by Hukuda et al. ${ }^{13}$ and Arlet and Arbiteboul ${ }^{14}$ showed a relation between the two syndromes, and they concluded that PLL ossification is only a local manifestation of DISH, that in some cases can precede further disease. ${ }^{13}$ In a recent case Johnson and colleagues ${ }^{15}$ described an ossified anterior longitudinal ligament and a PLL from D6 to D9, the last one very similar to our case.

These reports support our impressions that in our case of AS the meningeal calcification and associated cauda equina syndrome are related to DISH, though a cauda equina syndrome has not yet been described in DISH.

\section{References}

1 Bowie E, Glasgow G. Cauda equina lesions associated with ankylosing spondylitis. $\mathrm{Br}$ Med $J$ 1961; ii: 24-7.

2 Rosenkranz W. Ankylosing spondylitis: cauda equina syndrome with multiple spinal arachnoid cysts. J Neurosurg 1971; 34: 241-3.

3 Lynn Russell $M$. The cauda equina syndrome of ankylosing spondylitis. Ann Intern Med 1973; 78: 551-4.

4 Gordon A. Cauda equina lesion associated with rheumatoid spondylitis. Ann Intern Med 1973; 78: 555-7.

5 Thomas D J, Kendall M J, Whitfield A G W. Nervous system involvement in ankylosing spondylitis. $\mathrm{Br}$ Med $J$ 1974; i: $148-50$.
6 Hassan J. Cauda equina syndrome in ankylosing spondylitis: a report of six cases. J Neurol Neurosurg Psychiatry 1976; 39: 1172-8.

7 Cumming W, Saunders M. Radiculopathy as a complication of ankylosing spondylitis. J Neurol Neurosurg Psychiatry 1978; 41 : $569-70$.

8 Kramer L, Krouth G. Computerised tomography: an adjunct toos early diagnosis in the cauda equina syndrome of ankylosingD spondylitis. Arch Neurol 1978; 35: 116-8.

9 Young A, Dixon A. Cauda equina syndrome complicating్ ankylosing spondylitis. Use of electromyography and computerized tomography in diagnosis. Ann Rheum Dis 1981; 40: 317-22.

10 Grimaldi A. Syndrome de la queue de cheval compliquant unc spondyloarthrite ankylosante. Nouv Presse Med 1981; 10: 3572.

11 Weinstein P. Spinal injury, spinal fracture and spinal stenosis in ankylosing spondylitis. J Neurosurg 1982; 37: 609-16.

12 Acquaviva P, Monier M C, Ginesy R, Serratrice G. Aspects $\triangle$ radiologiques du crâne dans l'hyperostose vertebrale. In:L'Appareil locomoteur normale et pathologique dans la deux $\mathrm{N}$ ième moitié de la vie. $V I^{e}$ Conference Internationale d'Aix-les $V$ Bains. Geigy. 1980: 269-75.

13 Hukuda S, Schichikava K, Mochizvki T. Cervical hyperostotic myelopathy and its surgical treatment. In: L'Appareil locomoteur normale et pathologique dans la deuxième moitié de lo vie. VI Conference Internationale d'Aix-les-Bains. Geigy. 1980 284-91.

14 Arlet J, Arbiteboul M. Retrecissement du canal rachidien efo hyperostose vertebrale ankylosante. In: L'Appareil locomoteuN normale et pathologique dans la deuxième moitié de la vie. VI Conference Internationale d'Aix-les-Bains. Geigy. 1980: 276-83

15 Johnson K E, Peterson H, Wollheim A, Släveland H. Diffuse idiopathic skeletal hyperostosis (DISH) causing spinal stenosis and sudden paraplegia. J Rheumatol 1983; 10: 784-9. 